\title{
On Tolerance and Fictitious Publics
}

\author{
May Thorseth
}

\section{Introduction}

One particular incidence makes up the main background for the argument to be presented below. On July 22 in 2011 Norway faced a tragedy of enormous dimensions. The right winged terrorist Anders Behring Breivik bombed the governmental building in Oslo, the capitol of Norway, and later the same day he cold-bloodedly killed 77 youth of the Norwegian Labour party who attended a summer camp on a small island outside Oslo. In the aftermath it was much debated in the medias how he could possibly be able to carry out this misdeed. We shall leave out all practical aspects here and rather concentrate on one particular moral issue, having to do with toleration. More specifically I shall frame this as a question whether we could possibly tolerate the political opinion upon which this action was based.

Breivik's opinions had been presented in a Manifesto online long before July 22. The author here laid out a conspiracy theory about the threat from inferior races against Arian and European people, and seriously discusses how to solve this problem. Much of his speech is right wing propaganda, presented in a quasi-dialogic form where Breivik interviews himself. Part of the story is his claim that he represents an Heraldic Order lead by himself. Without getting into further details I shall describe this Manifesto as employing fictitious use of reason. One of the issues in the trial was whether there had ever been others but the author himself being a member of this Order. Few believe that there are. For the sake of argument we shall assume that the whole story was fictional - there had never been any real public.

The main issue is then whether it makes a difference if the public is fictitious, as in Breivik's case, or rather a real public in the sense of consisting of a certain amount of people. I believe it is not. The most important criterion of the fictitious character is not the amount of participants, but rather the use of reason involved. Thus, the difference between the real and the fictitious is procedurally defined.

\footnotetext{
M. Thorseth $(\varangle)$

Department of Philosophy, Norwegian University of Science and Technology,

Trondheim, Norway

e-mail: may.thorseth@ntnu.no 


\section{New Publics and the Old Problem of the Public?- Digital Transition}

Due to the digital transition of communication medias of our time we can see how Dewey's problem of the public is going through a transition (Dewey 1927). Briefly, the problem of the public has to do with a political complexity that calls for improvement of the methods and conditions of debate, discussion and persuasion. Dewey recognised in particular a need for a better-informed public and also for legislators and policy makers to become better informed of the experiences of the public. On Dewey's account there is a risk that people do not to a sufficient degree acquire an adequate view of the public. As an example, both electors and voters lack the methods and conditions of debate to become sufficiently well informed. Raising this problem within the context of our new medias adds still another dimension to this old problem: everyone with access to the Internet is in principle able both to access all the information people may wish for, but on the other hand there is also an accelerating problem of filtering, as discussed by e.g. Cass Sunstein (2001).

Rather than conceiving of the problem of the public as one about having the most adequate methods and conditions for debate at hand the new problem is somehow the reverse: due to digital transition and the methods available today it would in principle have been possible to inform the public better. Truly, e-democracy and better communication between e.g. electors and voters have been tremendously facilitated. But the problem of the public still seems to have survived due to the same methods, despite their ability to facilitate information flows. Because people in liberal, democratic societies have freedom of speech and expression along with other democratic goods there is a possibility for everyone of accessing only the information one takes an interest in. Due to the information technologies of today it is even possible to publish one's own Daily $M e$, Sunstein's spooky vision of a fragmented society devoid of social glue (Sunstein, 2001). The possibility of everyone publishing their own tailor-made newspapers online is the nightmare Sunstein fears. Despite the methods at hand he envisages a society devoid of citizens taking upon societal duties towards their fellow citizens. Below I shall argue that Breivik's Manifesto is an example of a Sunsteinian Daily Me.

\section{New Medias and Blurring of Private-Public}

Since long the distinction between private and public has existed in the literature, in particular in debates between liberals and communitarians on multi-ethnic topics, e.g. in the debate on group rights (see e.g. Rawl 1985; Taylor 1994, and numerous other publications). One purpose of the divide has been to clarify questions of legitimate intervention in the private sphere. On a liberal account the private sphere has been identified with comprehensive goods such as religion and world outlook (Rawls), whereas the political domain is seen as possible to separate from the 
private, domestic life and keep it neutral in the sense of treating everyone equally. Susan Moller Okin has argued that this liberal separation between the spheres is insufficient to avoid suppression in the private, domestic areas of life. She has described this as a tension between multiculturalism and feminism (Okin 1999). Others, like Taylor, have discussed the problem of multiculturalism and recognition, i.e. of how to recognize everyone equally while at the same time respecting differences (Taylor 1994). On the one hand everyone should be given an equal right to exercise comprehensive goods. However, if a member of e.g. an ethnic or religious group disapproves of the comprehensive goods of that particular group she could be deprived of the same right that is admitted at the political level. Thus, we could no longer speak of equal recognition. The contradictory result would be that equal recognition at the political level is internally linked to disrespect of the individual group members. Thus, we can see how the public-private divide raises serious problems in the multicultural debate on toleration. Should conflicts in the private domain be exempted from public scrutiny in cases where individual are being deprived of their basic legal rights? What about cases of indoctrination, censorship and the like? In the context of this paper it is particularly the rights and duties connected with being well informed that is at stake. My bold claim is that the problem of the public prevails as long as citizens are deprived of the possibility of being well informed. A key question is of course whether a corresponding duty exists, i.e. whether we could reasonably speak of a responsibility to be informed about opinions diverging from one's own.

At his point we need to make a distinction between two understandings of 'well informed'. One relates to knowledge of e.g. others' opinions. The other concerns capability of reflection, of making well informed judgments. It goes without saying that these are related. For our context it is, however, the latter understanding we shall keep in focus. The main reason why is because it is possible to be well informed of the "facts" of a case without necessarily knowing better in the sense of judging better. The point of being better informed within deliberative democracy debates is about the latter (see e.g. Dryzek 2000).

Within the digital environments of today it is a trivial fact that most people are well informed simply because they have more information about a more extended range of issues compared to pre-digital times. But this epistemic point also contains a further question whether people thereby also have more knowledge. Rather than dwelling with this epistemic issue my point is rather a moral one: does more information indicate better knowledge? The case of Breivik rather proves the opposite. In his Manifesto he proves that he has a lot of information about historical "facts" and also of other viewpoints. The "dialogical" reflection carried out in the Manifesto is, however, no dialogue between himself and his opponents. What is obviously lacking is a capability of incorporating opposing and diverging opinions in developing his own ideology put forth in his document. Still, most people would agree that he has a lot of information, and even knowledge of many historical events, while he is still insisting on an interpretation that is at odds with dominant liberal and democratic viewpoints. In describing the state of the arts, i.e. the threat from Muslims and others who do not fit into his race hygienic public, he describes a 
reality that strongly diverges from other people's descriptions. The fact that the surrounding society strongly disapproves of his understanding seems to have no impact on a possible revision on his part. This is a serious flaw because it undermines a necessary criterion of a real public, namely recognition of the possibility of being mistaken. Unless a connection is established to other viewpoints there is no genuine public reasoning. This gives us a criterion for distinguishing between real and fictitious publics. Breivik's alleged public belongs to the latter.

The well-established private-public distinction is no longer adequate in dealing with cases like Breivik's. As Sunstein correctly claims there exists a threat to public reason due to filtering, the point being that opinions that ought to be brought into the public remain concealed to the public, in the private domain of the comprehensive. Even if we accepted Rawls' distinction between the political and the comprehensive, or public and private, this would not help much in cases like this one. Rather, we need to question whether to approve of opinions presented in the public unless they convey publicizable opinions. My claim here is that we should not.

What I want to establish is a criterion for the possibility of misconstrued conceptions of public reasoning, and to confuse real with fictitious public reasoning. What seems to be lacking in Breivik's Manifesto is the viewpoint of opponents, and to meet with the claim on universalizability. Below we shall have a brief look at Kant's 'reflective judgments'.

\section{Reflective Judgment}

Before discussing further our main question - whether we should respect equally real and fictitious public reasoning - we shall have a closer look at Kant's concept of reflective judgment. I shall argue that the willingness to apply this capability is decisive for qualifying as real public reasoning, and thus worthy of being tolerated.

\subsection{The Universal of Reflective Judgment ${ }^{1}$}

In Kant's conceptual scheme judgments are of two different kinds: either they are determinant, as when something particular is subsumed under universal laws, or, by contrast, "[i]f only the particular is given and the universal has to be found for it, then the judgment is simply reflective" (Kant 1952, Introduction IV:18). The purpose of reflective judgment is not to determine anything; rather, it is to give itself a law. Hence, validity is gained through reflection of something particular as opposed to subsuming something under universal laws. This is partly because judgment, which is the topic of investigation in his Third Critique, is about empirical contingencies and not about universal laws of nature or final ends of freedom.

\footnotetext{
${ }^{1}$ Parts of this paragraph was first developed in Thorseth (2008).
} 
Judgment is one among three cognitive faculties, the other two being theoretical and speculative reason (along with sensibility and understanding) in the First Critique, and pure practical reason in the Second Critique. Kant's own focal point in his treatment of judgment is taste and the sublime, and applies first and foremost to art, as distinguished from nature (pure reason) and freedom (practical reason). As such, judgment primarily concerns the aesthetic domain of feelings of pleasure and displeasure, as opposed to the faculties of cognition and desire. As such, pleasure and displeasure can never make claims to objective necessity or a priori validity:

As with all empirical judgments, [pleasure or displeasure] is, consequently, unable to announce objective necessity or lay claim to a priori validity. ... [J]udgement of taste in fact only lays claim ... to be valid for every one. ... [O]ne who feels pleasure in simple reflection on the form of an object ... rightly lays claim to the agreement of everyone, although this judgment is empirical ....

The ground of this pleasure is found in the universal, even if subjective, condition of reflective judgment, according to Kant. One essential point is to be noted here: the judgment receives its validity from the anticipated agreement with every judging person.

The validity of judgments depends on the judging, and it is not valid for those who do not judge. Hanna Arendt puts this point forth, in emphasising that the claim to validity presupposes communication between self and others. Hence, a judgment's claim to validity can never extend further than the public realm of those who are members of it (Arendt 1968, p. 221). There are in particular two aspects concerning validity that should be noted here. One concerns the relation between the particular and the universal, whereas the other has to do with the public aspect of judgment. Any particular judgment is based in contingent and finite appeals that nevertheless may transcend the subjective conditions of the particular judgment. The potential for transcending the purely subjective condition is due to the communicative aspect of all judgments. Hence, reflective judgment is deeply founded in communication. For Kant himself reflective judgment is supposed to lay outside the political domain, whereas both Arendt and later Sheila Benhabib rightfully have argued that it should be extended to the faculties of politics and morality as well (Arendt 1968; Benhabib 1992).

To answer this challenge, we shall first have a look at Kant's own account. He introduces the concept sensus communis, which is a public sense and a critical faculty that takes account of the mode of representation in everyone else. This faculty is the power to make judgments for the purpose of public appeal, thereby avoiding the illusion that private and personal conditions are taken for objective:

This is accomplished by weighing the judgment ... with the ... possible judgments of others, and by putting ourselves in the position of every one else ... [abstracting] ... from the limitations, which contingently affect our own estimate (Kant 1952, § 40, p. 294).

\footnotetext{
${ }^{2}$ Kant (1952: VII, p. 32). Since I first wrote this paper I have become aware that the translation of 'erweiterte Denkungsart' as 'enlarged mentality' or 'enlarged thinking' might be unfortunate. Other translators (Pluhar and Guyer) instead apply the term 'broadened way of thinking', which seems to better capture the meaning of the German term.
} 
This way of thinking in the place of everyone else is called enlarged thinking. The power of judgment rests on a potential agreement with others. Judgments derive their validity from this potential agreement. According to Arendt:

This means, on the one hand, that such judgment must liberate itself from the "subjective private conditions", that is, from the idiosyncrasies which naturally determine the outlook of each individual in his privacy and are legitimate as long as they are only privately held opinions, but are not fit to enter the market place, and lack all validity in the public realm (Arendt 1968, p. 220).

Sensus communis may thus be compared to the procedure of universalization in the categorical imperative, which in a similar way appeals to a public sense through universalization.

The potential agreement with others along with the liberation from private subjective conditions is what enables intersubjective validity of judgments. The kind of communication at work in judgment is a different kind of relation between the particular and the universal. In Sheila Benhabib's words: "Judgment is not the faculty of subsuming a particular under a universal but the faculty of contextualizing the universal such that it comes to bear upon the particular" (Benhabib 1992, p. 132). I understand the "contextualizing of the universal" that Benhabib talks about as a claim to demonstrate how the universal appeal works in each particular context. As an example, a claim directed towards the authorities to make exceptions for some particular group of citizens may contextualise the universal by demonstrating how the particular case relates to other similar cases. Otherwise, contextualising the universal might appeal to others' imagination of putting themselves in the particular circumstances of others. Both Arendt and Benhabib agree on Kant's account of reflective judgment as far as the validity procedure for particular judgments are concerned. However, the kind of intersubjective validity that is derived should not only be restricted to the aesthetic domain of taste, as we have seen. The main reason why is due to the intersubjective appeal in all judgment that anticipates communication with others. Even if a person is alone in making up her mind, there is an anticipated communication with others with whom one must finally come to some agreement (Arendt 1968, p. 220).

The extension of reflective judgment to the public domain of reason in general is vital to the argument of this paper. One reason why is because legitimating of opinions in the public domain requires approval of other participants in the discourses and disputes going on. This might be interpreted either as agreement that an opinion is reasonable, or as actual agreement with some other's opinion. The main point here is the kind of approval contained in Habermas' theory that public opinion is moving towards increasingly stronger validity of public opinion rather than claiming actual agreement of opinions (Habermas 1990). Validity is then conceived as an on-going legitimating process whose ultimate arbiter is public reason itself. 


\subsection{Reflective Judgment and Real Public Reasoning}

A key question is whether the claim "to think from the standpoint of everyone else" in Kant's Third Critique should be interpreted as making an appeal to context, which is assumed in Arendt's extension of reflective judgment to the public faculty. Validity in the Kantian model is grounded in the universal communicability of particular judgments. Thus, it might be argued that the emphasis is still on universality rather than particularity conceived as context. Universality is, however, based in a public sense that is possible to share with others only to the extent that it is communicable and may thus gain universal validity. Thus, I think it makes good sense to interpret particularity in Kant's account of judgments as an appeal to the context of particular judgments, on topics concerning reason just as well as judgment. In other words, I see no good reason why reflective judgment should not apply to all of our cognitive faculties: understanding, judgment, and reason. I think it is important to interpret Kant's claim on universality as always context sensitive in a certain respect: to think from the standpoint of anyone will, by necessity, always be context dependent since the action will always take place in some particular context.

What is at stake is still the relation between the particular and the universal, and how the former derives validity by relating to the latter. The claim on universal validity in Habermas' discourse theory has been countered by some of his critics who have argued that the contextual conditions of communication are ignored in his model (Habermas 1996; Young 2002). The importance of transcending the merely private subjective conditions, however, appears to be recognised by both Habermas and his critics. Rather, what is contested concerns the role of the particular: as constituent and necessary of all kinds of judgment, or as contextual limitations of legitimate communication in public deliberation. In the following we shall explore the relation of Kant's faculties of cognition and maxims of common human understanding with public reason in deliberation.

\subsection{Kant's Maxims of Common Human Understanding}

A main concern in Kant is to explain the grounds and limits of human reason. In doing so, he holds practical use of reason to be the more fundamental, according to Onora O'Neill (1989). Practical use of reason is fundamental by enabling us to act autonomously, i.e. not to be ruled by external forces. The only limit to this freedom is the categorical imperative or the universalization principle. Likewise, we have connected reflective judgment to public reason by way of publicizability of particular judgments. This point is fundamental to understanding why public use of reason is of such importance. ${ }^{3}$ Basically, it is due to Kant's claim that the public use of reason should always be free. In order for our public use of reason to be free

\footnotetext{
${ }^{3}$ The distinction between public and private use of reason demarcates the difference between sensus communis and sensus privatus (O’Neill 1989, p. 45). The former is identified with enlarged
} 
we must look upon acts of communication as the proper objects of toleration. The reason why is because toleration is seen as a response to communication. This is a more profound concept of toleration as compared to viewing utterances by others as mere expressions. The basic point is that communication rather than expression is required in public reason. Part of this claim on freedom to make public use of reason builds on the maxims of common understanding: (1) to think for oneself, (2) to think from the standpoint of everyone else, i.e. enlarged thought and (3) always to think consistently (Kant 1952, § 40, p. 294). The first is the maxim of understanding, the second the maxim of judging, and the third the maxim of reason. All of these maxims of public reason are more profound than any other use of reason, and they are standards for addressing "the world at large" (O'Neill 1989, p. 48). In addressing the world at large reason accepts no external authority. It is this use of reason that is at work in judgment of particular situations, derived from the human capacity for reflective judgment.

Thus, we see how reflective judgment and enlarged thinking in Kant is basic to any other form of communication. This is the important point to be drawn from his model for validation in the public faculty, and it is particularly interesting because it gives an account of how reflection of particular situations and conditions can make a claim to validity. This holds true as far as the appeals put forth address a universal audience. By contrast, addressing only a restricted audience cannot make claim to something that is universally communicable. Still, private uses of reason may be legitimate for certain purposes. The important point to be made is that " $[\mathrm{t}]$ here are no good reasons for tolerating any private uses of reason that damage public uses of reason" (O’Neill 1989, p. 49). Thus, arguing with Kant, it would be legitimate to accept uses of reason that do not address the world at large- perhaps even by accepting external authorities — as long as they serve public reason. ${ }^{4}$

In returning to our case of Breivik's Manifesto, we clearly face an example of a kind of reason that is likely to damage public use of reason. Whether his use of reason should be considered private rather than public is not the most important. In line with the distinction between real and fictitious outlined above I shall argue that the fictitious even more than the private character of Breivik's use of reason is the more important. Not only is it an attempt to conceal that his opinion has not been exposed to public scrutiny; the method at hand, i.e. publication on the Internet, reinforces the impression of being public. This is particularly so as it resembles documents and uses of reason that are genuinely public in a Kantian sense. Reflective judgment and public use of reason is the liberation of our judgments from subjective private conditions, a necessary condition for weighing our judgments with the possible judgments of others, by putting ourselves in the position of every one else. Failing

thinking, addressing an unrestricted audience, while the latter is restricted, for instance, by filling the roles of clergy, officers, and civil servants.

${ }^{4}$ It is disputed whether public reason should be seen as a gradual process towards more enlightenment, which concerns the relation between the first and the third maxims of sensus communis: the maxim to think for oneself and the maxim to think consistently. If it is conceived in developmental terms, then we may envisage an ongoing process towards better understanding that can only be judged along the developmental line. 
to do this while arguing as if one's opinions qualify as public is the main flaw of Breivik's Manifesto. Still, as an expression within the public domain of utterances it remains to discuss whether we are in any sense obliged to tolerate it. As has been argued in the ongoing debate of liberal democratic freedom of expression there seems to be no substantive criterion for drawing a line. Instead this paper is an attempt to establish a procedural criterion for toleration.

\section{Responsibility and Tolerance at Stake}

From the argument developed above we shall move on to discussing why public reason should be tolerated, as opposed to fictitious public. Tolerance is here based on a positive account of it (Addis 1997). Much in line with the positive account of freedom Addis' concept of positive tolerance requires action or engagement. Another concept for positive tolerance applied by Addis is 'pluralistic solidarity' (Addis 1997). ${ }^{5}$ Briefly, to tolerate means to engage with those we disagree with, not only to leave them alone, or allow them to remain aliens. According to this understanding tolerance requires genuine communication, i.e. connecting with others' opinions. Lack of such a relation does not necessarily call for disrespect, though. The point here is to identify what expressions should count as worthy of dialogical engagement, and thus become part of public reason.

Breivik's Manifesto clearly appears not to be meant for public reason in our sense. The message is a claim on an unchallenged truth or ideology about the state of the arts for Europe in particular. The primary aim in his mind is to save Europe from the threat of dangerous ideologies, in particular the Muslim. But isn't such a fear legitimate, and why would it not be worthy of respect or tolerance? I will try to clarify this point by comparing Breivik with another character whose opinions were also not challenged by opposing viewpoints.

\subsection{Stefan Arkadievitch vs. Anders Behring Breivik}

The character to be compared to Breivik is Stephan Arkadievitch, a fictional character in Leo Tolstoy's Anna Karenina. He never changed his mind, or the newspapers he used to read. He never questioned the sources that he made use of for being informed. He picked the newspapers that suited his class and his position. Thus, he never run the risk of being forced (by some better argument) to change, and even less to improve, his opinions. If he changed opinions it was solely due to the papers he read-and any such change he compared to changing his hat! (Tolstoy 1886). In this character we see the kind of citizen that gives rise to the problem of the public.

\footnotetext{
${ }^{5}$ Addis' concept 'pluralistic solidarity' builds upon the concept of positive freedom, cf. Isaiah Berlin (1958/1969), Charles Taylor (1994).
} 
Even though Breivik, unlike Arkadievitch is deeply involved with political issues, they are both operating in a way that demonstrates the problem of the public.

The relevant similarity in the two cases is that 'technologies' in some sense seem to prevent them from being better informed. While Tolstoy's character believes that he is being sufficiently well informed through the media channels available to him, Breivik in a similar way acts as a media institution himself (cf. Cass Sunstein's Dailey $\mathrm{Me}$ ). Relevant information that could have informed them better is clearly missing in both of these two cases.

We are normally used to thinking that public institutions like medias not only provide us with relevant information, but as well that they provide us with improved qualified information. Neither Arkadievitch nor Breivik, however, seem to bear witness to becoming better informed or more knowledgeable in a relevant sense. Like in Breivik's case, Tolstoy's character also access only the information he wants to, i.e. he always reads the papers that will confirm his preconceived viewpoints, according to what he has defined in advance to be suitable for someone of his position. Like Arkadievitch, Breivik also sticks to opinions he already accepts to be true. In a similar manner they both avoid having their viewpoints challenged by opposing opinions. In a likewise manner both Breivik and Tolstoy's character seem to be immune to counterarguments, and they both appear to stick to the opinions that are predicated, either by the class one belongs to (Arkadievitch) or by the person himself (Breivik). Still, I shall argue that there is a relevant difference between the two cases: referring to what is suitable to one's own class or position presupposes some communicative relation to the surrounding community, as opposed to Breivik's case, as the latter seems to be more or less secluded from any communicative community.

There are two related, but still different phenomena involved in this comparison. On the one hand there is the possibility and risk of filtering, which certainly differ in the two cases, but this difference is one of degree. Stefan Arkadievitch' opinions are based on a high degree of filtering, and so are Anders Behring Breivik's opinions, although to an even higher degree. However, when it comes to seclusion there is a difference between the two cases, which is not only one of degree, but also of quality. This difference is the one described above, which I have spoken of as a difference between a real and a fictitious public. The Breivik case is not only a media problem as such, rather it has to do with a blind belief in the possibility of creating a public by way of new technologies. Thus the digital transition and the new medias seem to add something to Dewey's old problem of the public. ${ }^{6}$

\footnotetext{
${ }^{6}$ At this point I would like to point to Luciano Floridi's concept of hyperhistory which I find helpful in grasping the radical difference between medias before and after the digital transition. Floridi makes the point the hyperhistory is characterised by social wellbeing being dependent on ICT. Following this line of thought we may view Breivik as a grotesque illustration of this point. Had he lived in history - e.g. at Stefan Arkadievitch' time - it's doubtful whether medias by then would have contributed to his wellbeing the way the Internet has made possible.
} 


\subsection{Tolerance of Real or Fictitious Publics?}

From the above I shall assume that Stefan Arkadievitch participates in a real public, as opposed to Anders Behring Breivik who is a member of a fictitious public, mainly unfolding in virtual environments. The main distinction between the two 'realities' is not, however, whether they are virtual as opposed to real, but rather whether thay are fictitious as opposed to public. The use of reason is still to some extent public in Arkadievitch' case, while fictitious as far as Breivik is concerned. However, although the virtual character of the communication is not the main source of the problem, there still seems to be a non-trivial connection between virtual environments and a fictitious public, as virtual realities appear to be a necessary, though not a sufficient condition for fictitiousness.

It could easily be argued that the distinction between the real and the fictitious equals the difference that could be drawn between the real and the virtual. ${ }^{7}$ This is, however, misleading, as a virtual reality may very well be communicative in e.g. a Habermasian sense, where communication is based on public use of reason. As an example there have been several occasions of political activist actions starting with mobilizing people in a virtual world online before spreading offline (Thorseth 2006). By contrast, the public in Breivik's case is based in fictitious use of reason, while pretending to make appeals to a real and universal audience.

As mentioned earlier, Cass Sunstein and many others have written extensively on the problem of filtering and group polarisation. A distinction between real and virtual worlds is anticipated to be the relevant distinction, and the virtual tends to be associated with a radical threat to public reason. From the arguments above I shall claim that this is partly misconceived, as the real threat rather has to do with fictitious publics. Against this one could of course object that the fictitious character needs not necessarily be associated with a threat to public reason since there need not necessarily be an internal link between extreme ideologies and their fictitiousness. This is the reason for my claim that the fictitious character should be procedurally defined. The fictitious character of a claimed public should be defined by its communicative methods. As a consequence it is an open issue whether fictitious publics need to prevail.

This procedural criterion is based on an argument developed in Thorseth, arguing in favour of a distinction between legitimate and illegitimate paternalism in polyethnic conflicts (Thorseth 1999). Briefly, the salient point is that a claim on publicizability is basic to recognition. Unwillingness to discuss publicly what has already become contested in the public domain is in some cases based on procedural fundamentalism, as e.g. depriving others of autonomous "yes" of "no". ${ }^{8}$ Here I want to establish that real and virtual publics are not moral opposites, while the contrast

\footnotetext{
${ }^{7}$ A thorough analysis of the charachter of the virtual is discussed in Ess and Thorseth (2011).

${ }^{8}$ This claim is based on Habermas' argument against apriorily defined group rights because autonomous accept or refusal may thereby be curtailed. As an example, everyone should be allowed not to consent to norms and practices that have hitherto been passed over from previous generations (Habermas 1994).
} 
between real and fictitious clearly is: a qualified "yes" of "no" may be genuine or real in a virtual world, even though the consenter knows that a simulation is going on. This is different in the fictitious case where alternative options of choice seem to be missing. As an example, people may very well be able to produce their Daily $M e$ while still being aware that they are making this choice consciously. In Breivik's case, like many other fundamentalist cases we have no good reason to believe that their Daily Me results from a non-conscious choice, rather the opposite. This may be so whether they act in a real or a virtual world, i.e. whether they address a real or a virtual audience. The upshot of this argument is then that the real/virtual distinction is not of vital importance in defining the real/fictitious distinction. This may sound trivial, but I believe it is no, as the virtual character of the new media technologies is often believed to be the main source of damage to public reason. Virtuality may be associated with creativity and offer possibilities of broadened reasoning, while the fictitionality described above rather tends to work in an opposite direction. ${ }^{9}$ As for now the salient point is the ways fictitious publics diverge from real publics in our discussion of public use of reason.

One serious concern discussed in this paper is the risk of a real confusion of arguments as if they were part of public reason. In the aftermath of the Breivik case this risk has been expressed in terms of the influence this case- - both the Manifesto and the trial- has on a broader public of people holding extreme ideological viewpoints. I shall argue that this risk of private use of reason as if it were public is part of the problem of the public in the realm of digital transition. Recalling Onora O'Neill's concept of publicizability and Kant's distinction between private and public use of reason she claims that publicizable communication is "in principle accessible to the world at large and can be debated without invoking authority". ${ }^{10}$ The universalizability claim attached to this constraint certainly is absent in Breivik's case.

\section{Concluding Remarks}

The main concern discussed here is the possibility of producing arguments as if they were part of public reason in online environments; as if they qualified for addressing a universal audience. To make something publicly availably is not to be confused with publicizability in O'Neill's sense. Dissemination of a Manifesto at the Internet is thus not necessarily publicizable. The difference between 'publicly available' and 'publicizable' becomes particularly urgent given the new information technologies of our times. Breivik's Manifesto is in this sense made possible due to the digital transition, and it is as such a result of living in hyperhistory, in Luciano Floridi's

\footnotetext{
${ }^{9}$ See Thorseth (2008) for a discussion of public reason and broadened way of thinking.

${ }^{10}$ O'Neill (1989, p. 34). Authority here refers to the authority of reason, as opposed to external autorities.
} 
sense. ${ }^{11}$ For humans to live in the hyperhistorical era then implies a dependence on ICTs as fundamental for wellbeing, also when it comes to communication itself. If this analysis is correct we may envisage a scenario where the welfare of citizens depend on their capability to master the new technology. But does it necessarily also imply that we are left without any means of distinguishing between legitimate and illegitimate modes of communicating? I think not. But in order to maintain a human society we need to be able to draw the line between tolerable and non-tolerable modes of public reasoning. In this paper I have tried to sketch a strategy towards establishing this line, by identifying fictitious use of public reason as a mode of communication that should not be tolerated.

The virtual is not the real enemy; rather it is the ideological aspect linked to fictitious publics - the main reason being the possibility of ideological and fictitious "publics". A further question arising from this claim is, however, whether the kind of "publics" in view could exist without the digital and virtual environments. My thesis is that they could not, thus pointing to a genuinely new aspect of Dewey's problem of the public. Floridi's concept of hyperhistory presented above is helpful in understanding how the digital transition in a radical way has changed the conditions of public reasoning. Whether the environments are virtual or "real" is less important.

My claim in this paper has been that the threat to public reason of today basically has to do with the possibility of creating fictitious publics. As argued above the real threat to public use of reason is not the virtual worlds online per se. The decisive criterion is whether we are facing a fictitious public without effective means of recognizing it. The argument developed here hopefully contributes to help identifying the problem of the public in an era of digital transition.

Open Access This chapter is distributed under the terms of the Creative Commons Attribution Noncommercial License, which permits any noncommercial use, distribution, and reproduction in any medium, provided the original author(s) and source are credited.

\section{References}

Addis, A. 1997. On human diversity and the limits of toleration. In Nomos XXXIX: Ethnicity and group right, ed. I. Shapiro and W. Kymlicka. New York: New York University Press.

Arendt, H. 1968. Crisis in culture. In Between past and future: Eight exercises in political thought, ed. H. Arendt. New York: Meridian.

Benhabib, S. 1992. Situating the self. Cambridge: Polity Press.

\footnotetext{
${ }^{11}$ Floridi (2012): "[T]o summarise, human evolution may be visualised as a three-stage rocket: in prehistory, there are no ICTs; in history, there are ICTs, they record and transmit data, but human societies depend mainly on other kinds of technologies concerning primary resources and energy; and in hyperhistory, there are ICTs, they record, transmit and, above all, process data, and human societies become vitally dependent on them and on information as a fundamental resource"(author's italics).
} 
Berlin, I. 1958/1969. Two concepts of liberty. In Four essays on liberty, ed. I. Berlin. Oxford: Oxford University Press.

Dewey, J. 1927. The public and its problems. New York: Henry Holt \& Co.

Dryzek. J. 2000. Deliberative democracy and beyond. Liberals, critics, contestations. Oxford: Oxford University Press.

Ess, C., and M. Thorseth. 2011. Trust and virtual worlds. Contemporary perspectives. New York: Peter Lang.

Floridi, L. 2012. Hyperhistory and the philosophy of information policies. Philosophical Technology 25:129-131.

Habermas, J. 1990. Moral consciousness and communicative ethics. Cambridge: MIT Press.

Habermas, J. 1996. Between facts and norms. Cambridge: M.I.T. Press.

Kant, I. 1952. The critique of judgment. (Transl. J. M. Meredith, 1952). Oxford: Clarendon.

Okin, S. M. 1999. Is multiculturalism bad for women? Princeton: Princeton University Press.

O'Neill, O. 1989. Constructions of reason. Explorations of Kant's practical philosophy. Cambridge University Press.

Rawl, J. 1985. Justice as fairness. Political not metaphysical. Philosophy and Public affairs 14 (3):223-251

Sunstein, C. 2001. Republic com. Princeton University Press.

Taylor, C. 1994. Multiculturalism. Examining the politics of recognition. Princeton: Princeton University Press.

Thorseth, M. 1999. Legitimate and Illegitimate Paternalism in Polyethnic Conflicts. Gothenburgh. Acta Universitatis Gothoburgensis.

Thorseth, M. 2006. Worldwide deliberation and public use of reason online. Ethics and Information Technology, 8:243-252.

Thorseth, M. 2008. Reflective judgment and enlarged thinking online. Ethics and Information Technology 10:221-231.

Thorseth, M. 2011. Global communication online against fundamentalist knowledge offline? In Fundamentalism in the Modern World, eds. U. Mårtensson, J. Bailey, P. Ringrose, and A. Dyrendal, 25-49, vol 2. London: I. B.Tauris.

Tolstoy, L. 1886. Anna Karenina. New York: Thomas Y. Crowell \& Co.

Young, I. M. 2002. Inclusion and democracy. Oxford: Oxford University Press. 